\title{
Spirituality and Marital Satisfaction in African American Couples
}

\author{
Frank D. Fincham and Christine Ajayi \\ The Florida State University
}

\author{
Steven R. H. Beach \\ University of Georgia
}

\begin{abstract}
This study examined the relationship between spiritual experiences of African Americans and their marital quality. Couples $(N=487)$ completed measures of marital quality as well as a daily spiritual experience measure and an index of religiosity. Using the standard Quality Marriage Index, actor and partner effects were found for both spouses, and these remained when religiosity was controlled. Support was also obtained for two separate dimensions of marital quality comprising evaluations of positive and negative aspects of the relationship. Husbands' spirituality was strongly inversely related to own negative marital quality whereas actor effects for wives were almost equal in absolute magnitude for both dimensions. Taking overall marital quality into account, the spirituality-negative dimension association was significantly stronger for husbands than wives. These results are discussed in terms of behaviors that may enhance spiritual experiences and factors that may mediate their relationship to marital quality.
\end{abstract}

Keywords: marital satisfaction, spirituality, African American, religion

Most African Americans value marriage, and the benefits of marriage for African Americans have been well documented (e.g., Clayton, Glenn, Malone-Colon, \& Roberts, 2005; Littlejohn-Blake \& Darling, 1993). Yet the rate of African Americans residing in married-couple families has declined dramatically in recent decades (Brown, Orbuch, \& Bauermeister, 2008; Pinderhughes, 2002; Zollar \& Williams, 1987), and the divorce rate of African Americans within the first 10 years of marriage exceeds that of Whites $(47 \%$ vs. $32 \%$, Bramlett \& Mosher, 2001). In addition, among those who are currently married, African American couples consistently report lower satisfaction than do White couples (Acitelli, Douvan, \& Veroff, 1997; Roebuck \& Brown, 2007) or Black Caribbean couples (Bryant, Taylor, Lincoln, Chatters, \& Jackson, 2008).

This article was published Online First May 30, 2011.

Frank D. Fincham and Christine Ajayi, Family Institute, The Florida State University; Steven R. H. Beach, Psychology Department, University of Georgia.

This paper was supported in part by a grant from the John Templeton Foundation awarded to the first and third authors, and was also supported in part by a grant from the Administration for Children and Families to the first author.

Correspondence concerning this article should be addressed to Frank D. Fincham, Family Institute, Sandels Building, 120 Convocation Way, Florida State University, Tallahassee, FL 32306. E-mail: ffincham@fsu.edu
The decline of married-couple families may appear somewhat surprising, given that African Americans are markedly more religious than the general population on a variety of measures (Pew Charitable Trust, 2009; see also Chatters, Taylor, \& Lincoln, 1999; Hunt \& Hunt, 2001), and religiosity is associated positively with relationship quality for married couples (e.g., Wolfinger \& Wilcox, 2008; Wilcox, 2004; Christiano, 2000). Religion has both direct and indirect associations with marital quality. The direct relations include increased social support of norms and values of marriage and relationship-enhancing behaviors (e.g., partner forgiveness), while indirect effects include fostering increased psychological well-being, temperance, and sexual fidelity (Wolfinger \& Wilcox, 2008). To the extent that promarriage attitudes generate trust between partners, they should also encourage greater spousal investment in the marriage (Edin \& Kefalas, 2005; Wilcox \& Nock, 2006).

Historically, our understanding of marital quality among African American married couples has been limited owing to a research literature dominated by studies on White middleclass families and a disproportionate focus on negative relationship processes (Boyd-Franklin, 2003; McAdoo \& Younge, 2008; Watson \& Protinksy, 1988; for a general discussion, see Fincham \& Beach, 2010a). Recently, greater attention has been paid to investigation of mar- 
riage in more diverse samples and to the study of protective factors that are distinct for African American marriages (Fincham \& Beach, 2010b). Given the historical importance of the church in the African American community, an understandable interest has surfaced in the role of religion and spirituality in African American marriages.

Using data from the National Comorbidity Survey, Kiecolt, Hughes, and Keith (2008) found that African Americans attended church more often than Whites, and church attendance was significantly associated with a reduction in mental illness. In addition, Ano and Vasconcelles (2005) found that spirituality may influence positive affect in regard to coping with life stressors. Although these broad trends are important, there is a disconnect between the larger implications of spirituality for the health of African Americans and current knowledge about the spirituality-marital satisfaction association.

\section{Spirituality and African Americans}

Several studies have examined the role of religiosity and spirituality in the lives of African Americans (Boykin \& Ellison, 1995; Brown, Ndubuisi, \& Gary, 1990; Dickson, 1993; Quander, 2000). In this research, a distinction has emerged between religion and spirituality. For example, Emblen (1992, p. 45) noted that "spirituality is the personal life principle that animates transcendent quality of relationship with God or god being as religion is a system of organized beliefs and worship that a person practices." In other words, religion is often used to refer to a more formalized set of ideological commitments associated with a group (i.e., an organized system of beliefs, rituals, and cumulative traditions within a faith community), whereas spirituality is often used to refer to the personal, subjective side of religious experience (e.g., Carlson, Kirkpatrick, Hecker, \& Killmer, 2002; Worthington \& Aten, 2009).

Although both religion and spirituality may serve as conduits for the other, spirituality has been shown to capture domains that measures of religiosity may not be able to capture (Mattis, 2000). For instance, church attendance or affiliation may not capture the spiritual process that has been shown to envelope and permeate the African American experience (Newlin, Knafl, $\&$ Melkus, 2002). However, most people con- sider themselves to be both religious and spiritual; between two thirds and three fourths of Americans consider themselves to be both spiritual and religious (Marler \& Hadaway, 2002). Not surprisingly, Moberg (2005) reports that there is a growing consensus regarding the need to study spirituality and religiousness together.

Spirituality appears to serve as a buffer for life stressors that are more acute for African American couples: economic deprivation, structural racism, and oppression (Bean, Perry, \& Bedell, 2002; Boyd-Franklin, 2003; Diala et al., 2001; Franklin, 2004). Spirituality has been an important part of the African American experience, and its corporate manifestation through religion provides one of the few institutions some African American couples have access to and trust (Boyd-Franklin, 2003; McAdoo, 1991). The church has consistently impacted lives of African Americans socially, economically, and politically (Taylor, Thornton, \& Chatters, 1987).

Lichter and Carmalt (2008) found that it may be more important that couples share the same beliefs compared to simply the same religious affiliation. Couples who participated together and were actively engaged in their faith communities reported higher quality relationships. Although it has been important to gain an understanding of religiosity and marital satisfaction, spirituality has been explored less and may have stronger implications for relationship processes.

The experience of spirituality appears to differ by gender (Mattis, 2000; Wilcox, 2004). Giblin (1997) found that men's spirituality was related to their marital relationship more directly, compared to the complex implications that spirituality had for wives. He compared the varied experiences based on gender to triangles and circles:

Self, other, and God were the three points, with men
more likely to take the relationship with their wives to
God in prayer, while wives seemed more frequently to
take the relationship with God back into the marriage.
Wives also seemed much less comfortable with the
triangle image, opting instead for a circle and a more
internal, mysterious, and less easily described sense of
presence. (p. 330)

Married men who reported high levels of spirituality also reported higher levels of marital satisfaction than their less spiritual counterparts. Not only that, their wives also reported higher 
levels of satisfaction within the relationship (Lichter \& Carmalt, 2008; Wilcox \& Wolfinger, 2007). Although this may appear intuitive, there is more that needs to be explored in regard to gender, spirituality, religion, and marital satisfaction among African American couples. For instance, lower levels of negative marital interactions are found in the relationships of men who regularly attend religious services. For women, it appears that benefits may only be seen when both they and their partners attend (Wilcox \& Wolfinger, 2007).

In light of the above observations, this study explored potential gender differences in spirituality and its relationship to marital satisfaction. Unfortunately, the few existing studies of African American marriage tend to examine husband and wife outcomes in separate analyses, thereby yielding a truncated view of the way spouses may influence each other in marriage. In contrast, we utilize the Actor Partner Interdependence Model that takes into account the dependency between husband and wife data (Kenny, Kashy, \& Cook, 2006). A final innovation relates to the close relationship between spirituality and religiosity: Specifically, we attempt to show that spirituality does not simply serve as a proxy index of religiosity.

\section{Marital Satisfaction}

Marital satisfaction has tended to be investigated as a one-dimensional, static entity. Measures of relationship satisfaction typically comprise self-report items that solicit global evaluative judgments about the relationship (e.g., "indicate the degree of happiness, all things considered, of your relationship") on a bipolar response scale (e.g., ranging from "Extremely Unhappy" to "Perfectly Happy"). Such scales assume an inverse relationship between favorable and unfavorable evaluations. That is, endorsing favorable evaluations (e.g., somewhat happy) is equivalent to the rejection of unfavorable ones (i.e., somewhat unhappy). This reduces the definition of relationship satisfaction to the relative absence of relationship dissatisfaction, and vice versa. Such bipolar scales create interpretive difficulties. For example, it is unclear whether responses at the scale midpoint represent indifference (i.e., neither highly favorable nor unfavorable evaluations) or ambivalence (i.e., opposing evaluations held simultaneously).
A variant of this unidimensional approach attempts to quantify satisfaction alone without mentioning dissatisfaction. Thus, for example, Lichter and Carmalt (2008, p. 5) asked one question to measure marital satisfaction in their study: "Now think about your overall relationship with your spouse. On a scale of $0-10$ where 0 is not at all satisfied and 10 is completely satisfied, taking all things together how would you describe your relationship with your partner?" Although this allows for greater clarity in interpretation of responses, this approach is also problematic. This is because most relationships comprise both satisfying and dissatisfying characteristics (e.g., Orden \& Bradburn, 1968) and, hence, individuals likely hold both favorable and unfavorable evaluations about their relationship simultaneously. Fincham and colleagues (Fincham, Beach, \& Kemp-Fincham, 1997; Fincham \& Linfield, 1997) therefore conceptualized relationship satisfaction as two separate dimensions comprising evaluations of the positive (i.e., satisfying) and negative (i.e., dissatisfying) aspects of the relationship. They hypothesized that assessing these two dimensions independently of one another would provide additional information on current relationship functioning that could not be obtained from traditional unidimensional measures like the Marital Adjustment Test (MAT; Locke \& Wallace, 1959) and Dyadic Adjustment Scale (Spanier, 1976).

To test their hypotheses, Fincham and Linfield (1997) developed two 3-item scales to assess each of these dimensions: the Positive Marital Quality (PMQ) and the Negative Marital Quality (NMQ) scales. They found that the PMQ and NMQ items conformed best to an oblique two-dimensional latent structure versus a solution in which all items loaded onto a single evaluative factor. Also, the separate PMQ and NMQ dimensions predicted unique variance in self-reports of dyadic behavior and relationship attributions beyond that which was accounted for by the Marital Adjustment Test (MAT; Locke \& Wallace, 1959). Using the two-dimensional measure developed by Fincham and Linfield (1997), Mattson, Paldino, and Johnson (2007) showed that it captured well the relationship quality of engaged couples and accounted for unique variability in observed behavior and attributions. For example, the negative dimension predicted men's observed nega- 
tive affect and women's observed positive affect while holding constant variance associated with the positive marital quality dimension and a unidimensional measure of relationship quality.

This bidimensional approach provides a more nuanced picture than that offered by unidimensional measures of marital satisfaction. Moreover, it echoes Pinderhughes's (2002) work on African American intimate relationships. She noted that men and women in romantic relationships tend to take out their frustrations within their relationships, although they also report high levels of satisfaction and view their marital relationship as satisfactory. To date, however, research on African American marriages is limited to study of unidimensional measures of marital satisfaction. Whether a bidimensional approach is appropriate in the study of African American marriages is unknown, as it cannot be assumed that the structure of marital satisfaction found with Whites is applicable. The present study provided the first attempt to document a two-dimensional structure to marital quality among African Americans.

\section{Overview of Study}

The goal of this study was to explore the relationship between spiritual experiences of African American partners and their marital quality. To facilitate comparisons with prior research, we included a widely used unidimensional scale of marital satisfaction. We hypothesized that spiritual experiences would predict overall marital quality. However, we also investigated the structure of marital quality using Fincham and Linfield's (1997) measure. It was hypothesized that marital quality would show the same structure as that found in prior samples. Finally, we hypothesized that men's reports of spiritual experiences would be a stronger predictor of satisfaction for both them and their partner.

\section{Method}

\section{Participants}

The participants in this study were 487 African American couples (married $=430$, engaged $=57$ ) that represented both urban and rural sections of the southeastern United States. The data obtained is from a larger study, The
Program for Strong African American Marriages (ProSAAM). To be included in the study, participants self-identified as African American or were in a relationship with an African American, were at least 21 years of age, and either engaged to be married or married at least one year prior to the recruitment period. Men varied in age from 21 years to 77 years $(M=39.87$, $S D=9.70)$ and women's ages varied from 20 to 61 years $(M=38.22, S D=9.18)$. The measures that are used in this study were collected at a baseline assessment before the implementation of a preventive intervention study.

\section{Procedure}

Couples were recruited through direct advertising, participating in community-based recruitment events, distributing brochures to businesses, appearing on local radio shows, obtaining local press coverage, and involving local pastors in attracting couples to the program. Pastors were recruited by allowing them to evaluate the program and then endorse it from the pulpit. This approach led to opportunities to recruit in a variety of settings, including church meetings, Bible studies, worship services, and other church events.

Trained field interviewers conducted in-home interviews with participants. After interviewers reviewed the consent procedures with participants, the ProSAAM battery was given. Participants were reminded that their involvement was voluntary and they could withdraw at any time. The subjects were compensated $\$ 25$ for completing the measures. All items on the measures were presented and read from a computer by the interviewer. The respondents entered their answers on a separate keypad.

\section{Measures}

Spirituality. The Daily Spiritual Experience Scale (DSES) was used to assess spirituality (Underwood \& Teresi, 2002). It is a 16-item scale that measures the frequency of spiritual experiences using a scale that ranged from 1 (many times a day) to 6 (never or almost never). Items were recoded so that higher scores reflect more spiritual experiences. Example items from the Daily Spiritual Experience Scale are "I feel thankful for my blessings," and "I feel guided by God in the midst of daily activities." In the present sample, coeffi- 
cient alpha was .94 for husbands and .95 for wives.

Religiosity. Religious participation was measured using two items assessing degree of participation in church-related activities during the preceding 30-day period. Participants rated the frequency of religious activity on a scale from 1 (daily) to 5 (never) in regard to attendance at worship services and attendance in classes or discussion groups on religion. Responses to the two items were significantly correlated for husbands, $r(485)=.54, p<$ .001 , and for wives $r(485)=.49, p<.001$. They were therefore summed to form an index of religiosity such that higher scores indicated greater religious involvement.

Marital satisfaction. The Quality of Marriage Index (QMI) was used to assess marital satisfaction (Norton, 1983). This inventory assesses marital quality with broadly worded, global items (e.g., "We have a good marriage"). Respondents show their degree of agreement with each of five items on a 7-point Likert-type scale from 1 (very strong disagreement) to 7 (very strong agreement) and with one item on a 10-point Likert-type scale from 1 (very strong disagreement) to 10 (very strong agreement). In the present sample, coefficient alpha was .94 for husbands and .96 for wives.

The Positive and Negative Quality in Marriage Scale (Fincham \& Linfield, 1997) was also used to measure marital satisfaction. This measure was used because of its sensitivity to two-dimensional processes of satisfaction in marital relationships (Fincham \& Linfield, 1997). Each item asks respondents to evaluate one dimension at a time and to ignore the other dimension. For example, one positive item states, "Considering only the positive feelings you have toward your mate, and ignoring the negative ones, how positive are these feelings?" Negative items are phrased similarly but ask respondents to focus on the "bad feelings" while ignoring the "good ones." Respondents selected answers that ranged from 0 (not at all) to 10 (extremely). Responses were summed to form a composite score. Higher scores indicate more positive or more negative perceptions of marital quality. In the present sample, coefficient alpha was .94 and .91 on the negative dimension scale for wives and husbands, respectively. On the dimension that scaled positive satisfaction, al- pha was .90 and .87 for wives and husbands, respectively.

\section{Results}

Because responses from husband and wife are not independent, the data were analyzed using the Actor Partner Interdependence Model (APIM, Kenny et al., 2006) for distinguishable dyads. This model allows the potential impact of spirituality on own marital quality to be estimated (actor effects) as well as the potential impact of each spouse's spirituality on the partner's marital quality (partner effects).

\section{Spirituality and Marital Quality}

Our first analysis examined spirituality and marital quality as measured by the Quality of Marriage Index (QMI). This was done to investigate our research question with a widely used, standard instrument that measures satisfaction along a single dimension. Exogenous variables in the model were husbands' and wives' spirituality scores, with spouses' QMI scores serving as endogenous variables. Spouses' level of spirituality was associated with their own reports of marital satisfaction $(B=.33$ for husbands; $B=.26$ for wives) as well as partner reports of satisfaction (wives to husbands, $B=$ .18 ; husbands to wives, $B=.14$ ). Constraining corresponding actor and partner effects to be equal did not result in a significant decrement in model fit, showing that there were not any significant gender differences.

Spirituality: Religiosity by another name? It might be argued that the prior findings simply use spirituality as a proxy index for religiosity and therefore offer nothing new. This argument appears to have some merit, as the correlation between religiosity and spirituality was significant for both husbands, $r(485)=.26, p<.001$, and wives, $r(485)=.27, p<.001$. However, husband spirituality and wife spirituality were weakly related (.09), whereas husband and wife religiosity were strongly related (.46), and the magnitude of the two correlations differed significantly, $z=6.32, p<.001$.

To further examine the question posed, we repeated the APIM analysis reported earlier substituting our measure of religiosity for the measure of spirituality to see if we obtained the same pattern of results. Husbands' religiosity 
was associated with their own reports of marital satisfaction $(B=.19)$ and wives' reports of satisfaction $(B=.18)$. However, unlike the model for spirituality, no significant actor $(B=$ $.04)$ or partner effect $(B=.06)$ was found for wives. It therefore appears that spirituality and religiosity yielded distinct patterns of findings.

But do these patterns hold in a multivariate context when both spirituality and religiosity are included in the same model? To answer this question, we computed a model that included actor and partner effects for both spirituality and religiosity. In this model, all actor $(B=.30$ for husbands; $B=.25$ for wives) and partner effects (wives to husbands, $B=.17$; husbands to wives, $B=.11$ ) were significant for spirituality, as was found when it was examined alone. The pattern of findings for religiosity also remained the same in that actor $(B=.12)$ and partner effects $(B=.15)$ were found for husbands but not wives. It thus appears that spirituality is not simply a proxy index of religiosity and that one construct cannot be considered a substitute for the other at the empirical level.

Is marital quality bidimensional? A confirmatory factor analysis (CFA) was conducted in which positive and negative items loaded on separate factors to test whether our satisfaction measure reflected two dimensions. This model provided an adequate fit to the data for both husbands, $\chi^{2}(8)=32.3$, CFI $=.98$, RMSEA $=$ .07 , and wives, $\chi^{2}(8)=44.7$, CFI $=.98$, RMSEA $=.09$. To further examine whether a two-factor model is more appropriate than a unidimensional model, a model comparison procedure introduced by Bollen (1980) was used. By comparing the hypothesized twofactor model to a model where the zero-order association between the two dimensions of marital quality is constrained to be one (thereby positing a single factor), two- and one-factor models can be compared by interpreting the change in chi-square (per change in degrees of freedom) as a chi-square statistic. When the association between positive and negative dimensions was constrained to unity, there was a poor fit to the data for husbands, $\chi^{2}(9)=759.4$, $\mathrm{CFI}=.69$, RMSEA $=.27$ and wives, $\chi^{2}(9)=$ $970, \mathrm{CFI}=.70$, RMSEA $=.313$. Allowing positive and negative dimensions to covary resulted in a significant change in chi-square for a one degree of freedom change for both husbands and wives (husbands, $\Delta \chi^{2}(1)=722.1$; wives, $\left.\Delta \chi^{2}(1)=925.3\right)$. This finding is consistent with our hypothesis that a two-dimensional structure of marital satisfaction can be applied to African American marriages. Correlations and descriptive statistics for the two dimensions are shown in Table 1.

\section{Spirituality and Two Dimensions of Marital Quality}

The results from the confirmatory factor analysis provided reason to examine spirituality in relation to our two-dimensional satisfaction model. Spouse scores on the Daily Spiritual Experience Scale served as exogenous variables, and the two dimensions of satisfaction for husband and for wife were endogenous variables.

As predicted, spousal levels of spirituality were positively associated with own PMQ ( $B=$ .26 for husbands; $B=.25$ for wives) and inversely related to own NMQ $(B=-.35$ for husbands; $B=-.22$ for wives). Partner effects were also significant. Husbands' levels of spirituality were directly related to wives' PMQ $(B=.13)$ and inversely related to their NMQ $(B=-.16)$. In a similar vein, level of wives' spirituality was directly related to husbands' PMQ $(B=.11)$ and inversely related to their NMQ $(B=-.12)$. There were no gender differences in actor or partner effects.

Finally, we examined whether spirituality accounted for variance in PMQ and NMQ dimensions over and beyond that which can be explained by a standard unidimensional satisfaction measure. This is particularly relevant given the substantial correlations between the QMI and the PMQ (.65 and .71 for husbands and wives, respectively) and NMQ dimensions ( -.66 and -.76 for

Table 1

Partners' Reports of Positive and Negative Dimensions of Marital Satisfaction: Correlations and Descriptive Statistics $(n=487)$

\begin{tabular}{lrrrr}
\hline \multicolumn{1}{c}{ Variables } & \multicolumn{1}{c}{1} & \multicolumn{1}{c}{2} & 3 & 4 \\
\hline 1. Positive (Wife) & \multicolumn{1}{c}{-} & & & \\
2. Positive (Husband) & .33 & - & & \\
3. Negative (Wife) & -.51 & -.30 & - & \\
4. Negative (Husband) & -.24 & -.44 & .40 & - \\
$M$ & 4.94 & 5.07 & 2.33 & 2.03 \\
$S D$ & .95 & .78 & 1.13 & .96 \\
\hline
\end{tabular}


husbands and wives, respectively). We therefore added each spouse's QMI scores as exogenous variables to the model predicting PMQ and NMQ dimensions. Husband spirituality still yielded a significant actor effect $(B=-.15)$ for NMQ and a marginally significant $(B=.06$, $p<.065$ ) actor effect between wife spirituality and PMQ. When the corresponding actor effects for the NMQ were constrained to be equal, there was a significant decrement in model fit, $\Delta \chi^{2}(1)=4.7, p<.05$, showing that this effect differed for husbands and wives. These findings suggest that spirituality may be particularly important in decreasing husbands' negative evaluation of the marriage and somewhat important for wives' positive evaluation of the marriage.

\section{Discussion}

This study examined the relationship of spirituality to relationship satisfaction in African American couples using cutting-edge measures and dyadic analytic tools. To provide continuity with existing data, the association was first examined with a widely used unidimensional measure of marital satisfaction-the Quality of Marriage Index. Consistent with prior research, husband religiosity was particularly important in that it related not only to own but also wife satisfaction. Spirituality, however, was related to both own and partner satisfaction for both husband and wife data. Finally, the relationships documented for spirituality could not be accounted for by religiosity, and vice versa. Thus, at an empirical level, spirituality and religiosity operated somewhat independently despite some conceptual overlap and their perceived covariation in the general population. Of particular interest was the divergence between religiosity and spirituality with regard to couple correspondence. Whereas religiosity appeared to function as a couple variable, with partners showing similar levels of religiosity, spirituality could be seen as an individual variable that was not necessarily shared between spouses.

No prior research has examined marital quality on two evaluative dimensions for a sample of African American couples, and, hence, the applicability of a bidimensional structure for marital quality was also tested. Consistent with past research using White samples (Fincham \& Linfield, 1997; Mattson et al., 2007), the data supported the existence of a positive marital quality dimension and a negative quality dimension for both husbands and wives. Dyadic analyses were then used to assess the extent to which spirituality served as a predictor variable for not only positive marital quality but also negative experiences of relationship quality using the Actor Partner Interdependence Model. This allowed us to explore, in greater detail, the finding that higher levels of spirituality are connected to experiences of relationship quality (Wilcox, 2004; Wolfinger \& Wilcox, 2008). Our APIM analysis suggests that men's level of spirituality may be particularly important in regard to their negative marital quality, as this path yielded the highest actor effect $(-.35)$. For wives, the relationship of spirituality to both dimensions of satisfaction was almost equal in absolute magnitude ( -.25 and .22). Interestingly, in regard to partner effects, the largest effect again involved husband level of spirituality and the negative dimension of marital quality. Thus, for both husband actor effects and partner effects, the association appears to be particularly strong for negative marital quality. For wives, the absolute magnitude of spirituality on positive and negative quality is virtually the same for both actor and partner effects. Although intriguing, this pattern of findings must be viewed cautiously in the absence of significant sex differences.

Given the prominence of spirituality in accounting for variance in marital quality, it is of particular interest for future work to better identify specific behaviors that may contribute to spirituality. One of these possible behaviors is prayer. In our own research, we have examined the effect of prayer on relationship outcomes and have found that prayer for the partner is both malleable and has an impact on couples (Beach et al., in press). We do not yet know, however, how prayer of this sort relates to reports of spirituality and whether the effects of spirituality on relationship quality are mediated by prayer for the partner or are independent of it.

It is also possible that spirituality has an effect on communication processes. For example, Beach, Fincham, Hurt, McNair, and Stanley (2008) argued that certain spiritual behaviors, when utilized in the context of conflict, could provide a specific mechanism that allows cooperative goals to regain their dominance, replacing revenge-oriented or competition-oriented 
ones. If so, this could provide a mediating link between spirituality and positive relationship outcomes. Alternatively, it may be that spirituality is associated with fewer perceived disagreements, and this may be true particularly when both spouses share similar levels of religiosity or spirituality. Likewise, spirituality may be associated with greater tendencies to forgive, along with the attendant benefits to the relationship that have been identified for forgiveness (see Fincham, 2009).

In each case, mediators of the impact of spirituality on relationship quality have the potential to further explicate the association and identify mechanisms that could be supported to further enhance the effect of spirituality on relationship quality. By the same token, the relatively less powerful effect of religiosity on marital satisfaction should not be taken as indicating that religiosity cannot have a substantial effect. Anecdotally, it appears that disagreements about religiosity can be a source of conflict in marital relationships, an observation supported by at least one study (Curtis \& Ellison, 2002). Perhaps more commonly, one spouse, often the wife, will attend services more frequently, and this has the potential to make church attendance an individual activity rather than a shared couple activity. If so, there may be effects of religiosity that were not adequately captured by the current analyses.

\section{Limitations and Implications for Future Research}

The primary limitation of this study is that it only includes data from one time point. Satisfaction within relationships is not a static entity, so inclusion of multiple time points would allow prediction of not only mean levels of satisfaction to be examined but also change in satisfaction. The correlational nature of the data also reduces the confidence with which causal inferences can be inferred. For example, it may be that levels of satisfaction within the relationship lead to increased or decreased spirituality. Longitudinal data are needed to determine how satisfaction and spirituality are connected over time. Additional limitations include reliance on self-report and lack of controls for demographic variables.

Given the association between marital quality and both mental and physical health, future research that takes an in-depth look into how spirituality can impact other important outcome variables for African Americans (i.e., parenting practices, communication, physical health) would also make a valuable contribution to this body of literature. In any event, a greater focus on African American couples is needed, especially in regard to strengths-based processes. In particular, there is need to investigate how African American men and women might experience spirituality differently. There are also implications for clinical practice. It has been accepted that incorporating spirituality into treatment with African American couples may be of benefit. This study adds to growing awareness that it may be relatively more important to allow for space for men to examine the role of spirituality in their lives and, in particular, its connection to their satisfaction with their partners.

\section{References}

Acitelli, L. K., Douvan, E., \& Veroff, J. (1997). The changing influence of interpersonal perceptions on marital well-being among Black and White couples. Journal of Social and Personal Relationships, 14, 291-304. doi:10.1177/0265407597143001

Ano, G. G., \& Vasconcelles, E. B. (2005). Religious coping and psychological adjustment to stress: A meta-analysis. Journal of Clinical Psychology, 61, 461-480. doi:10.1002/jclp.20049

Beach, S. R. H., Hurt, T. R., Fincham, F. D., Franklin, K. J., McNair, L. M., \& Stanley, S. M. (in press). Enhancing marital enrichment through spirituality: Efficacy data for prayer focused relationship enhancement. Psychology of Religion and Spirituality.

Beach, S. R. H., Fincham, F. D., Hurt, T., McNair, L. M., \& Stanley, S. M. (2008). Prayer and marital intervention: A conceptual framework. Journal of Social and Clinical Psychology, 27, 641-669. doi: 10.1521/jscp.2008.27.7.641

Bean, R. A., Perry, B. J., \& Bedell, T. M. (2002). Developing culturally competent marriage and family therapists: Treatment guidelines for nonAfrican-American therapists working with African-American families. Journal of Marital and Family Therapy, 28, 153-164. doi:10.1111/ j.1752-0606.2002.tb00353.x

Bollen, K. A. (1980). Issues in the comparative measurement of political democracy. American Sociological Review, 45, 370-390.

Boyd-Franklin, N. (2003). Black families in therapy: Understanding the African American experience (2nd ed.). New York, NY: Guilford Press.

Boykin, A., \& Ellison, C. (1995). The multiple ecologies of Black youth socialization: An Afrographic analysis. In R. L. Taylor (Ed.), African American 
youth: The social and economic status in the United States (pp. 93-128). Westport, CT: Praeger.

Bramlett, M. D., \& Mosher, W. D. (2001). First marriage dissolution, divorce, and remarriage: United States. Advance Data No. 323. Hyattsville, MD: National Center for Health Statistics.

Brown, D., Ndubuisi, S., \& Gary, L. (1990). Religiosity and psychological distress among blacks. Journal of Religion and Health, 29, 55-68. doi: 10.1007/BF00987095

Brown, E., Orbuch, T. L., \& Bauermeister, J. A., (2008). Religiosity and marital stability among Black American and White American couples. Family Relations, 57, 186-197. doi:10.1111/ j.1741-3729.2008.00493.x

Bryant, C. M., Taylor, R. J., Lincoln, K. D., Chatters, L. M., \& Jackson, J. S. (2008). Marital satisfaction among African Americans and Black Caribbeans: Findings from the National Survey of American Life. Family Relations, 57, 239-253. doi:10.1111/ j.1741-3729.2008.00497.x

Carlson, T. D., Kirkpatrick, D., Hecker, L., \& Killmer, M. (2002). Religion, spirituality, and marriage and family therapy: A study of family therapists' beliefs about the appropriateness of addressing religious and spiritual issues in therapy. The American Journal of Family Therapy, 30, 157-171. doi:10.1080/019261802753573867

Chatters, L. M., Taylor, R. J., \& Lincoln, K. D. (1999). African American religious participation: A multi-sample comparison. Journal for the Scientific Study of Religion, 38, 132-145. doi: $10.2307 / 1387589$

Christiano, K. (2000). Religion and the family in modem American culture. In S. Houseknecht \& J. Pankhurst (Eds.), Family, religion, and social change in diverse societies ( $\mathrm{pp}$. 43-78). New York, NY: Oxford.

Clayton, O., Glenn, N., Malone-Colon, L., \& Roberts, A. (2005). Consequences of marriages for African Americans: A comprehensive literature review. New York, NY: Institute for American Values.

Curtis, K. T., \& Ellison, C. G. (2002). Religious heterogamy and marital conflict-Findings from the national survey of families and households. Journal of Family Issues, 23, 551-576.

Diala, C. C., Mutaner, C., Walrath, C., Nickerson, K., LaVeist, T., \& Leaf, P. (2001). Racial/ethnic differences in attitudes toward seeking professional mental health services. American Journal of Public Health, 91, 805-807. doi:10.2105/AJPH.91.5.805

Dickson, L. (1993). The future of marriage and family in Black America. Journal of Black Studies, 23, 472-491. doi:10.1177/002193479302300403

Edin, K., \& Kefalas, K. (2005). Promises I can keep: Why poor women put motherhood before marriage. Berkeley, CA: University of California Press.
Emblen, J. (1992). Religion and spirituality defined according to current use in nursing literature. Journal of Professional Nursing, 18, 41-47. doi: 10.1016/8755-223(92)90116-G

Fincham, F. D. (2009). Forgiveness: Integral to close relationships and inimical to justice? Virginia Journal of Social Policy and the Law, 16, 357-384.

Fincham, F. D., \& Beach, S. R. H. (2010a). Of memes and marriage: Towards a positive relationship science. Journal of Family Theory and Review, 2, 4-24. doi:10.1111/j.1756-2589.2010.00033.x

Fincham, F. D., \& Beach, S. R. H. (2010b). Marriage in the new millennium: A decade in review. Journal of Marriage and Family, 72, 630-649. doi: 10.1111/j.1741-3737.2010.00722.x

Fincham, F. D., Beach, S. R., \& Kemp-Fincham, S. I. (1997). Marital quality: A new theoretical perspective. In R. J. Sternberg \& M. Hojjat (Eds.), Satisfaction in close relationships (pp. 275-304). New York, NY: Guilford Press.

Fincham, F. D., \& Linfield, K. (1997). A new look at marital quality: Can spouses feel positive and negative about their marriage? Journal of Family Psychology, 11, 489-502. doi:10.1037//08933200.11.4.489-502

Franklin, A. J. (2004). From brotherhood to manhood: How Black men rescue their relationships and dreams from the invisibility syndrome. New York, NY: Wiley \& Sons.

Giblin, P. (1997). Marital spirituality: A quantitative study. Journal of Religion and Health, 36, 333344. doi:10.1023/A:1027481125385

Hunt, L. L., \& Hunt, M. O. (2001). Race, religion, and religious involvement: A comparative study of Whites and African Americans. Social Forces, 80, 605-631. doi:10.1353/sof.2001.0098

Kenny, D. A., Kashy, D. A., \& Cook, W. L. (2006). Dyadic data analysis. New York, NY: Guilford Press.

Kiecolt, K. J., Hughes, M., \& Keith, V. M. (2008). Race, social relationships, and mental health. Personal Relationships, 15, 229-245. doi:10.1111/ j.1475-6811.2008.00195.x

Lichter, \& Carmalt. (2008). Religion and marital quality among low-income couples. Social Science Research, 38, 168-187.

Littlejohn-Blake, S., \& Darling, C. (1993). Understanding the strengths of African American families. Journal of Black Studies, 23, 460-471. doi: 10.1177/002193479302300402

Locke, H. J., \& Wallace, K. M. (1959). Short marital adjustment prediction tests: Their reliability and validity. Marriage and Family Living, 21, 251255. doi: $10.2307 / 348022$

Marler, P. L., \& Hadaway, C. K. (2002). "Being religious" or "being spiritual" in America: A zerosum proposition? Journal for the Scientific Study of Religion, 41, 289-300. doi:10.1111/14685906.00117 
Mattis, J. (2000). African American women's definitions of spirituality and religiosity. Journal of Black Psychology, 26, 101-122. doi:10.1177/ 0095798400026001006

Mattson, R. E., Paldino, D., \& Johnson, M. D. (2007). The increased construct validity and clinical utility of assessing relationship quality using separate positive and negative dimensions. Psychological Assessment, 19, 146-151. doi:10.1037/ 1040-3590.19.1.146

McAdoo, H. P. (1991). Family values and outcomes for children. The Journal of Negro Education, 60, 361-365.

McAdoo, H., \& Younge, S. (2008). Black Families. In H. Neville, B. Tynes, \& S. Utsey (Eds.) Handbook of African American psychology (pp. 103 115). Beverly Hills, CA: Sage.

Moberg, D. O. (2005). Research in spirituality, religion, and aging. Journal of Gerontological Social Work, 45, 11-40. doi:10.1300/J083v45n01_02

Newlin, K., Knafl, K., \& Melkus, G. (2002). African American spirituality: A concept analysis. Advanced Nursing Science, 25, 52-70.

Norton, R. (1983). Measuring marital quality: A critical look at the dependent variable. Journal of Marriage and the Family, 45, 141-151. doi: $10.2307 / 351302$

Orden, S. R., \& Bradburn, N. M. (1968). Dimensions of marriage happiness. American Journal of Sociology, 73, 715-731. doi:10.1086/224565

Pinderhughes, E. B. (2002). African American marriage in the 20th century. Family Process, 41, 269-282. doi:10.1111/j.1545-5300.2002.41206.x

Quander, L. (2000). Faith-based programs fight HIV/ AIDS in minority communities. HIV Impact (Winter), 1-2.

Roebuck, B. J., \& Brown, S. L. (2007). Race-ethnic differences in marital quality and divorce. Social Science Research, 36, 945-967.

Spanier, G. B. (1976). Measuring dyadic adjustment: New scales for assessing the quality of marriage and similar dyads. Journal of Marriage and the Family, 38, 15-28. doi:10.2307/350547

Taylor, R. J., Thornton, M. C., \& Chatters, L. M. (1987). Black Americans' perceptions of the sociohistorical role of the church. Journal of Black Studies, 18, 123-138.

Underwood, L., \& Teresi, J. (2002). The daily spiritual experience scale: Development, theoretical description, reliability, exploratory factor analysis, and preliminary construct validity using healthrelated data. Annals of Behavioral Medicine, 24, 22-33. doi:10.1207/S15324796ABM2401_04

Watson, M., \& Protinsky, H. (1988). Black adolescent identity development: Effects of perceived family structure. Family Relations, 37, 288-292. doi:10.2307/584564

Wilcox, W. (2004). Soft patriarchs, new men: How Christianity shapes fathers and husbands. Chicago, IL: University of Chicago Press.

Wilcox, W., \& Wolfinger, N. (2007). Then comes marriage? Religion, race and marriage in urban America. Social Science Research, 36, 569-589.

Wilcox, W. B., \& Nock, S. L. ( 2006). What's love got to do with it? Equality, equity, commitment and women's marital quality. Social Forces, 84, 1321-1345. doi:10.1353/sof.2006.0076

Wolfinger, N., \& Wilcox, W. (2008). Happily ever after? Religion, marital status, gender and relationship quality in urban families. Social Forces, 86, 1311-1337.

Worthington, E. L., \& Aten, J. D. (2009). Psychotherapy with religious and spiritual clients: An overview. Journal of Clinical Psychology, 65, 123-130. doi:10.1002/jclp.20561

Zollar, A., \& Williams, J. (1987). The contribution of marriage to the life satisfaction of black adults. Journal of Marriage and the Family, 49, 87-92. doi:10.2307/352673

Received June 28, 2010

Revision received March 21, 2011

Accepted March 29, 2011 